\title{
Newborn Examination
}

National Cancer Institute

\section{Source}

National Cancer Institute. Newborn Examination. NCI Thesaurus. Code C84749.

A general assessment of the overall health of a newborn. 